\title{
An Approach to Utilize Crust Leather Scrapes, Dumped into the Land, for the Production of Environmental Friendly Leather Composite
}

\author{
Shamsun Nahar ${ }^{1,2,}$, M. A. Khan ${ }^{3}$, R. A. Khan ${ }^{3}$, E. C. B. Abdullah ${ }^{4}$, M. J. H. Khan ${ }^{4}$,

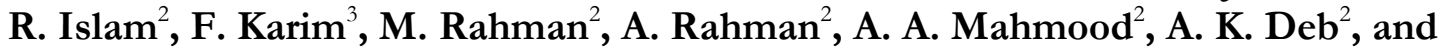 \\ U. H. B. Nahar ${ }^{2}$ \\ 1 Department of Materials and Metallurgical Engineering, Bangladesh University of Engineering and \\ Technology, Dhaka 1000, Bangladesh \\ 2 Bangladesh College of Leather Engineering and Technology, Dhaka 1000, Bangladesh \\ 3 Atomic Energy Center, Savar, Bangladesh \\ 4Department of Chemical Engineering, University of Malaya, Kuala Lampur 50603, Malaysia \\ *E-mail: shamshilpi@yahoo.com (Corresponding author)
}

\begin{abstract}
Among all the natural fiber, leather fiber is one of the animal fibers which is bearing hydrophilic and hydrophobic functional group. Leather is tanned with different types of chemicals and scraped crust leather containing chemical are coming from the leather industry after preparing footwear and leather products. In this research an attempt was taken to prepare composite with waste scrape crust leather. Leather fiber reinforced polyester resin based composites were prepared by wet layup method. Polyester content in the composite was varied from $100 \mathrm{ml}$ to $40 \mathrm{ml}$ and benzoyl peroxide was used as a radical initiator. Tensile strength (TS), Young modulus and elongation at break $\left(\mathrm{E}_{\mathrm{b}}\right)$ were measured. Tensile strength found to increase from 9.80 MPa to $10.85 \mathrm{MPa}$. Young's modulus was found highest in 70:5 ratios and it was $158.16 \mathrm{Mpa}$. Scraped crust reinforced composite will reduce the environmental pollution. So it can be concluded that scraped crust leather reinforced composite was found to have better result than matrix and reinforced material.
\end{abstract}

Keywords: Scraped crust leather, polyester resin, tensile strength, young modulus, environmental pollution.

ENGINEERING JOURNAL Volume 17 Issue 3

Received 27 September 2012

Accepted 6 February 2013

Published 1 July 2013

Online at http://www.engj.org/

DOI:10.4186/ej.2013.17.3.17 


\section{Introduction}

Composites are a versatile and valuable family of materials that can solve problems of different applications. They facilitate the introduction of new properties in materials. Recycling and renewing natural resources are giving a new dimension in discovering new materials [1-3]. In recent years, research interests are given on natural fiber reinforced polymer matrix composite instead of conventional inorganic fiber reinforced composite. In many cases natural fibers reinforced composites have good potential. The development of environment friendly 'green' materials is because of natural fiber's biodegradability, light weight, low cost, high specific strength compared to glass and carbon fiber. Fiber-reinforced composites are used in a variety of structural applications like aerospace, automotive parts, sports and recreation equipment, boats and office products, machinery, etc. For specific purposes specific characteristics materials are used and at the same time being non- polluting and environmentally friendly for that they becoming popular day by day due to the lack of resources and increasing environmental pollution [4-6]. In this study animal fiber i.e leather fiber was chosen as a reinforced in composite. Leather is natural polymer of amino acid monomer. For thousands of years, leather, as one of the collagen materials, has been among the most dominant fibrous materials used by humans. Leather is a general term for hide or skin with its original fibrous structure more or less intact, tanned or treated to be non-putrescible. The reason is to be found in the remarkable structure of leather, which is made up of millions of tiny string- like fibrils. Leather fibers are medium in length [7, 8]. Leather is a natural fiber but when it is finished then a lot of chemicals are incorporating into it. When this crust leather scrape is dumped the very quickly the chemical are releasing to the environment. After preparing the crust scrape leather composite, it will reduce the environmental pollution. For that reason leather industry plays a significant role in global economy. Leather is transformed into chemically and physically stable material by chemical and mechanical process. Our study investigates the properties of solid waste generated from different types of leather product - producing from industry i.e. garment, shoe upper, different leather products etc. Several researchers studied on leather waste and found that approximately $200 \mathrm{~kg}$ leather is manufactured 1 tone of wet-salted hide. More than $60 \%$ of rawhide weights are disposed to the environment by leather factories without turning them to good use. According to the Food and Agricultural Organization (FAO) data, it has been reveals that approximately 8.5 million tons of solid waste is generated during the production of 11 million tons of rawhide processed in the world [8-9]. For that in this study an attempt was taken to recycle this scraped crust leather for valuable composite. This composite will be fibrous composite. Dispersed phase of this composite is fiber which will improve strength, stiffness and fracture toughness of composite [10-12]. Matrix in such materials serves not only as a binder of the fibers but also keeping them in a desired shape and protecting them from mechanical or chemical damages. As tanned leather substance has low thermal stability $\left(\sim 110^{\circ} \mathrm{C}\right)$ for that polyester resin was chosen as a matrix.

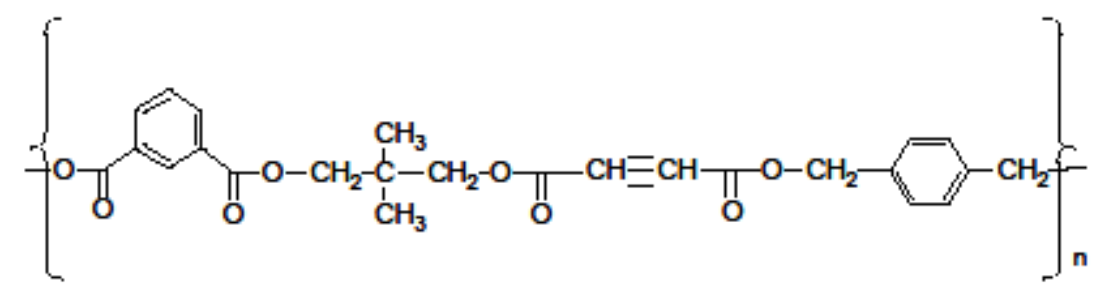

Initially the liquid resin is converted to a solid by cross-linking chains. This is done by creating free radicals at unsaturated bonds, which propagate in a chain reaction to other unsaturated bonds in adjacent molecules, linking them in the process. The initial free radicals are induced by adding a compound that easily decomposes into free radicals. However, in this research benzoyl peroxide has been added as an additive to improve the physico-mechanical properties of the composite. Benzoyl peroxide was used as a radical initiator. This benzoyl peroxide has improvement of physico-mechanical properties of the composite. Benzoyl peroxide (as an additive) has been reported in several research works, on natural fiber reinforced composite [10, 12-18]. The present work deals with the mechanical and morphological characteristics of the scrap crust leather reinforced polyester composite. 


\section{Experimental Method}

\subsection{Materials}

Crusted scrap leathers were collected from Hazaribag leather industry. These crusted scrap leathers were representing vegetable-tanned leather, chrome-tanned leather, aldehyde-tanned leather, synthetic-tanned leather, alum-tanned leather. Crusted scrap leather is shown in Fig. 1 Polyester resin for matrix was purchased from Polyolefin Company Limited, Singapore. Polyvinyl alcohol was purchased from Loba Chemie Private Limited, Mumbai, India Benzoyl peroxide was purchased from BDH, UK.

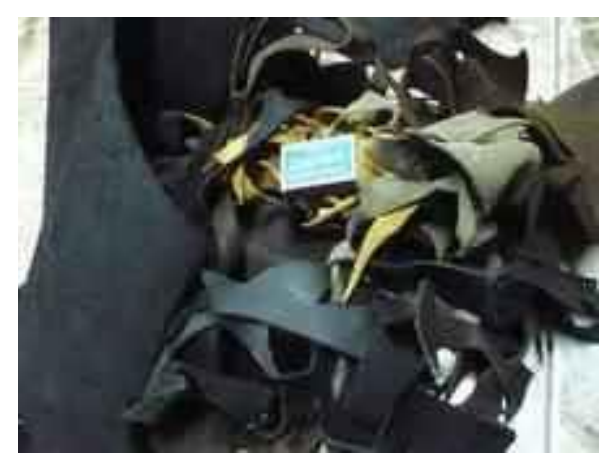

Fig. 1. Picture of Crusted scrap leather collected from industry.

\subsection{Preparation of Scrap Crust Leather}

For composite preparation at first the scrap crust leathers were ground two times in the grinding machine to obtain particle sizes of 300-500 microns.

\subsection{Preparation of Polyester Resin Solution}

In a beaker, $100 \mathrm{ml}$ of unsaturated polyester resin was taken. In another beaker $5 \mathrm{ml}$ of $10 \%$ PVA solution was taken and stirred for 10 minutes in stirring machine at heated to $100^{\circ} \mathrm{C}$. In the PVA solution beaker resin was poured to prepare the matrix of the composite.

\subsection{Preparation of Composite}

For the research purposes 6 samples of leather-polymer composite was fabricated and sample no 1 was only polyester resin. In the preparation of sample no: 2 , at first $5 \mathrm{gm}$ of ground scrap leather was taken in a beaker. In another beaker $100 \mathrm{ml}$ of unsaturated polyester resin was taken. In the second beaker $5 \mathrm{ml}$ of $10 \%$ PVA solution was taken and stirred for 10 minutes in stirring machine for mixing with resin to prepare the matrix of the composite. The matrix solution was then poured in the first beaker for mixing with the ground leather fiber. Again the mixture was stirred for 10 minutes in stirring machine. After that $1 \mathrm{ml}$ of benzoyl peroxide was added in the solution mixture and the final solution mixture was stirred for 5 minutes in the stirring machine. Finally the solution mixture was poured on to a polystyrene sheet $(30 \mathrm{~cm} \times 25 \mathrm{~cm})$. The solution mixture was sandwiched between the two polystyrene sheets. After that, required amount of load was applied on the polystyrene sheet with a steel plate to acquire a required thickness. The mixture is then left so that the resin will cure, usually at room temperature. To manufacture of sample no. 3, 4, 5, 6, 7 the same procedure was taken but the amount of resin are $90 \mathrm{ml}, 70 \mathrm{ml}, 60 \mathrm{ml}, 50 \mathrm{ml} \& 40 \mathrm{ml}$ respectively. So in sample 1 resin and fiber ratio was 100:0, in sample 2 resin and leather fiber ratio was 100:5, in sample 3 resin and fiber ratio was 90:5, in sample 4 resin and fiber ratio was 70:5, in sample 5 resin and fiber ratio 60:5, in sample 6 resin and fiber ratio was 50:5, in sample 7 resin and fiber ratio was 40:5. 


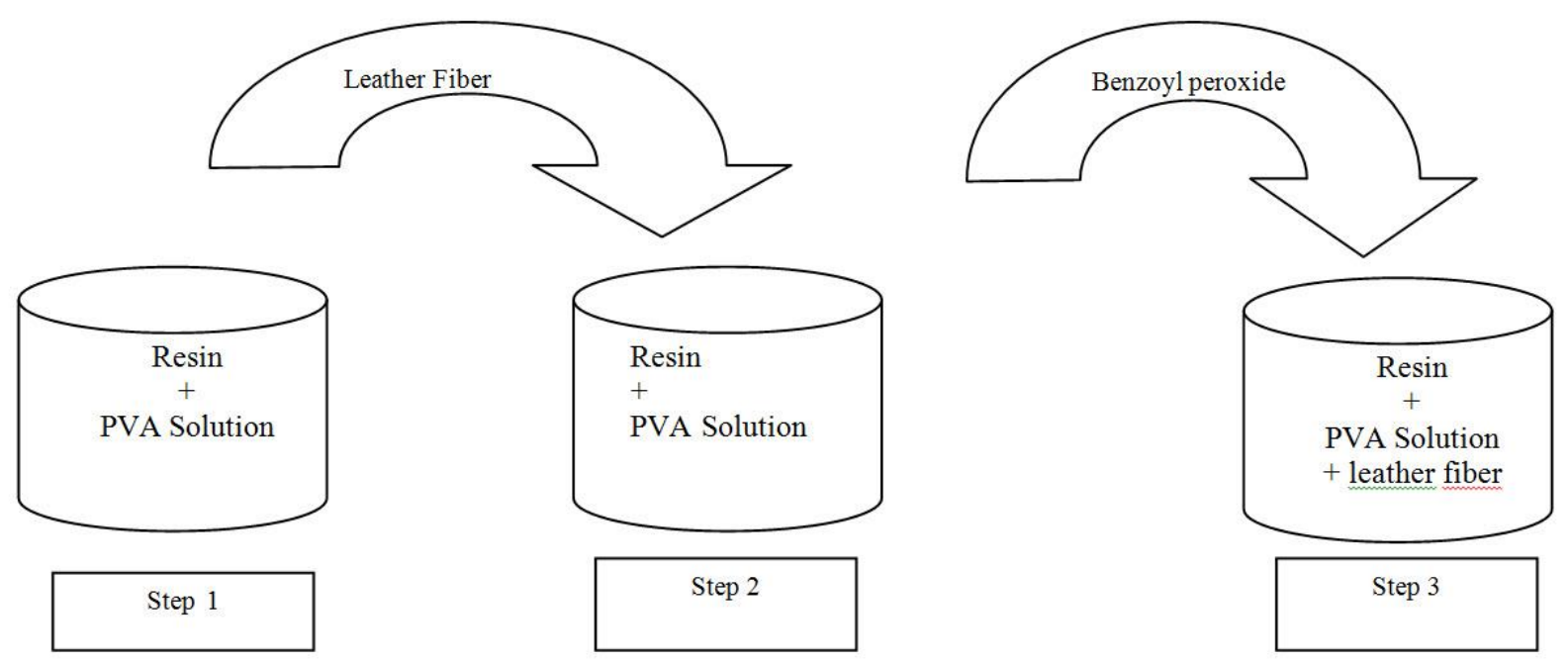

Fig. 2. Flow chart of fabricating crust scraps leather composite.

\subsection{Mechanical Properties}

The tensile and bending properties of the composites were determined according to DIN 53455 and DIN 53452 standard methods by a Universal Testing Machine (Hounsfield Series S, UK). The crosshead speeds used was $10 \mathrm{~mm} / \mathrm{min}$ for tensile strength and bending strength. At least 5 specimens were tested for each set of samples and the mean values are reported. The test samples were conditioned at $25{ }^{\circ} \mathrm{C}$ and $50 \%$ humidity for several days before testing. All the tests were performed using same environmental conditions.

\subsection{Microstructural analysis Scanning Electron Microscope}

Composite fracture part was dried at $100^{\circ} \mathrm{C}$ for to make moisture free. The non-conducting surface of the composites was coated with gold in agar auto sputter coater (model 108A, England) before subjected to Scanning Electron Microscope. The fiber matrix adhesion of the tensile fracture surface of the composites was examined by Scanning Electron Microscope (model XL 30, Philips, The Netherlands).

\section{Result and Discussion}

\subsection{Optimization of Crust Scrap leather Content in the Composites on the Basis of Their Mechanical Properties}

Optimization of crusted scrap leather content in the composites was done on the basis of their mechanical properties. Table 1 depicts the changes of the tensile strengths of the samples with the variation of the ratio of the matrix. It showed that the strength of the composite (100:5) increases than the polyester polymer (100:0). This suggests that the interfacial bonding between the fiber and the matrix is better in case of 100:5 composite. In case of 70:5 composite the tensile strength is higher than 100:5 composite, which means that the interfacial bonding was very good. But in the case of 60:5 composite the decrease of tensile strength is very high. This phenomenon indicates that the ratio of resin to fiber is not very interlinked at this point, so the interfacial bonding is not good. Again the tensile strength of 50:5 composite is better than 40:5 composite, which indicates that the tensile strength is dependent on the ratio of the resin to fiber. Table 1 shows the tensile strength (TS) with varying crusted scrap leather content of the composite. 
Table 1. Tensile properties of polyester and crusted scrap leather composites according to ratio (varying different ratio).

\begin{tabular}{ll}
\hline Sample & Tensile Strength (MPa) \\
\hline Sample $1(100: 0)$ & $9.8 \pm 0.25$ \\
Sample 2 (100:5) & $10.53 \pm 0.31$ \\
Sample 3 (90:5) & $10.64 \pm 0.53$ \\
Sample 4 (70:5) & $10.85 \pm 0.12$ \\
Sample 5 (60:5) & $6.65 \pm 0.37$ \\
Sample 6 (50:5) & $7.07 \pm 0.56$ \\
Sample 7 (40:5) & $5.34 \pm 0.38$ \\
\hline
\end{tabular}

Figure 3 represents that the Elongation at break at first decreases from point 100:0 to 70:5 . It indicates that up to this composition (decreasing region ) the ductility is decreasing, in another word stiffness is increasing. After that the increase of the Elongation up to 40:5 indicates that up to this composition (increasing region), the ductility is increasing. This is due to the amount of crosslink density. If the amount of crosslink density is decreased due to the loss of interfacial adhesion among the constituent phases in the blends, the tensile strength value is reduced with increasing the elongation at break.

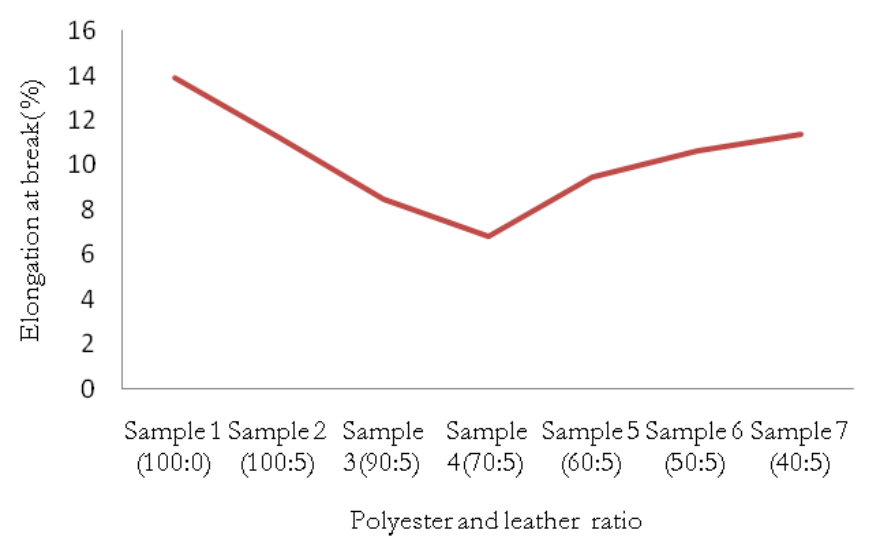

Fig. 3. Elongation at break (\%) of different ratio of composite.

Figure 4 represents that the Young's modulus at different ratio. At first increases from point 100:5 to 70:5. It indicates that up to this composition the fiber and the polymer are well distributed. The stiffness also increases in this region. After that the decrease of the Young's Modulus rapidly up to 40:5 indicates that up to this composition (decreasing region) the fiber and the polymer are not well distributed. The stiffness also decreases in this region [19-20]. Figure 5 is representing the external appearance of different ratio composite.

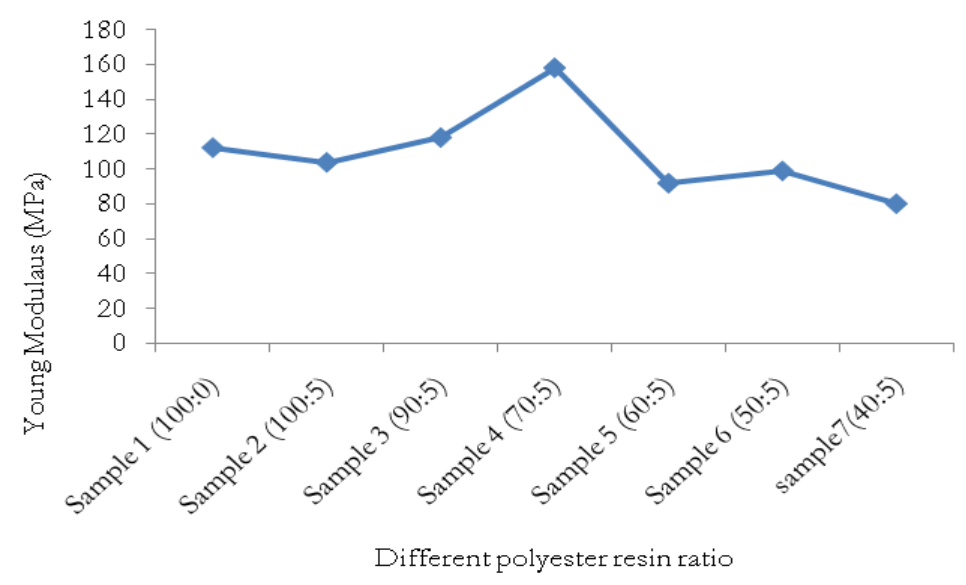

Fig. 4. Young's Modulus of different ratio of composite. 


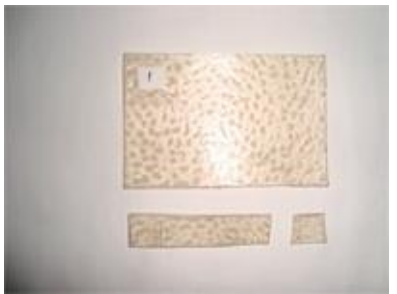

(a)

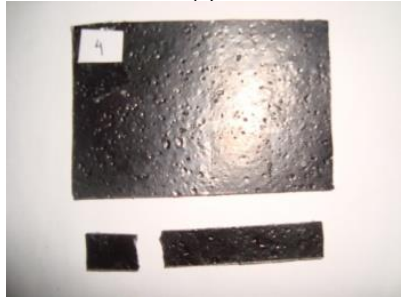

(d)

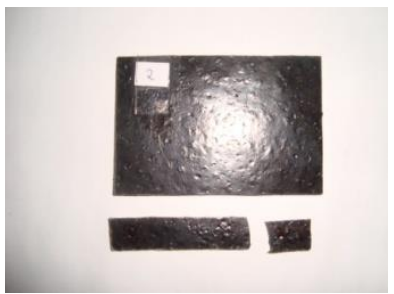

(b)

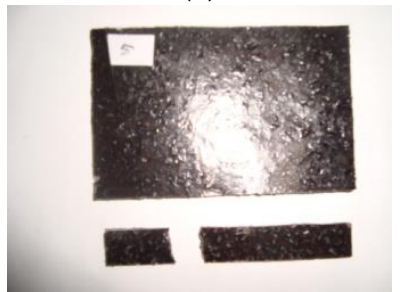

(e)

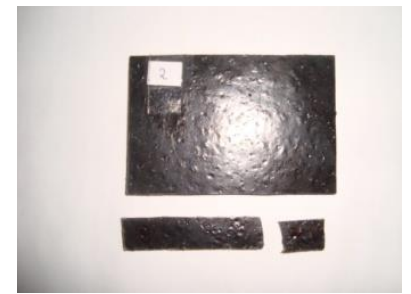

(c)

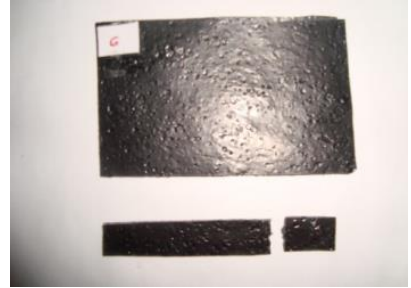

(f)

Fig. 5. Surface morphology of composite (a) only for polyester; (b) 100:5; (c) 90:5; (d) 70:5; (e) 60:5; (f) 50:5; (g) 40:5 for different ratio of polyester and leather composite.

\subsection{Scanning Electron Microscopy (SEM)}

SEM is considered an important tool in the study of composites since it can provide essential information about the degree of fiber-matrix adhesion and fiber dispersion in the matrix. SEM of the fracture surface of polyester and different ratio content composites are shown in Fig. 6(a) and (b)-(f), respectively. The fracture surface of the $100 \%$ polyester was found uniform in Fig. 6(a). In the fracture side some portion was observed very rough, some portion was observed rough and also some striation was also observed. This is very common phenomena of fracture surface. In Fig. 6(b) composition ratio was 100:5. Maximum portion of the fracture surface was shown to be uniform like Fig. 6 (a) and also some proportion was shown leather fiber. In this sample matrix and fiber interlock was observed. For that an increase in tensile strength and a decrease in $\mathrm{E}_{\mathrm{b}}(\%)$ was observed. Here matrix and reinforcement fiber interface interaction was observed. In Fig. 6(c) composition ratio was 70:5 which was found best result among all the ratio of the composition. In the micrograph of 70: 5 ratio there observed a very good dispersion of leather fiber with polyester matrix. Distribution of leather fiber in matrix was very uniform. Matrix phase was not observed markedly in this micrograph. For that in this sample high tensile strength was observed for the matrix reinforcement interaction. Elongation at break was found to lowest in this sample because of load was distributed between matrix and leather fiber [21]. For that Young's modulus was also found highest in this sample, because this sample has bearded the highest load and lowest strain. Figure 6(c) indicates that there were no fiber pull-out and fairly clean fiber surface was observed. Considerable amount of matrix polymer residue remains on the fiber was observed. Another aspect of the SEM photographs of the composites is fiber-matrix adhesion. The presence of polymeric links to the fibers is an indication of a strong fiber-matrix bonding, and, similarly, the lack of polymeric links represents a weak bonding. As shown in Figs. $6(\mathrm{~d}-\mathrm{f})$, in the fracture surfaces of the composite were seen that fibers were pull-out and no matrix adhering with fibers was observed. This result seems to indicate that the fiber-matrix adhesion is weak, maybe resulting from the lack of chemical reaction between the leather fibers and the polyester. Therefore, the fiber-matrix bonding is the result of mechanical interlocking between them. In this case, the stress transfer between the fibers and the matrix was due primarily to friction [22]. It is believed that an improved adhesion will be obtained if the leather fiber is surface-treated in further studies, and, hence, composites of higher strength can be prepared. 


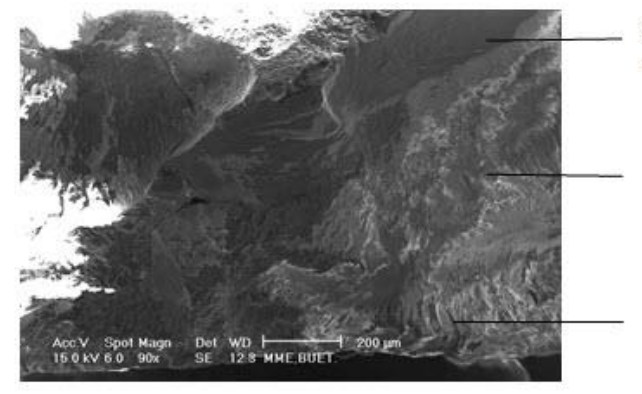

(a)

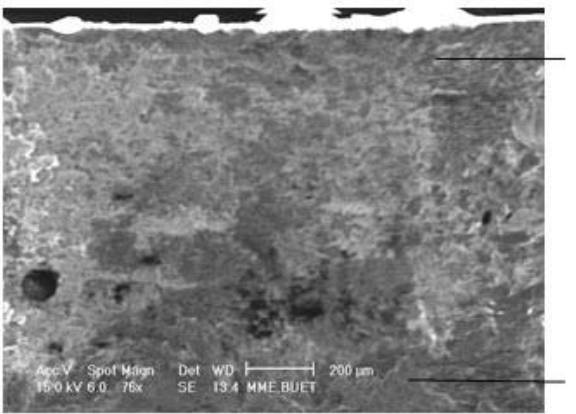

(c)

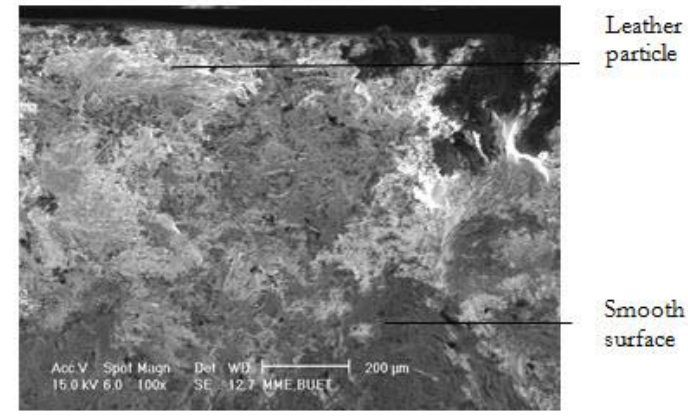

(e)

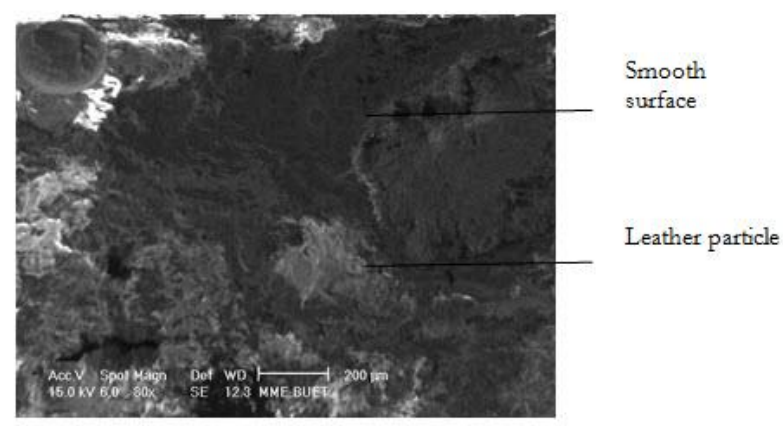

(b)

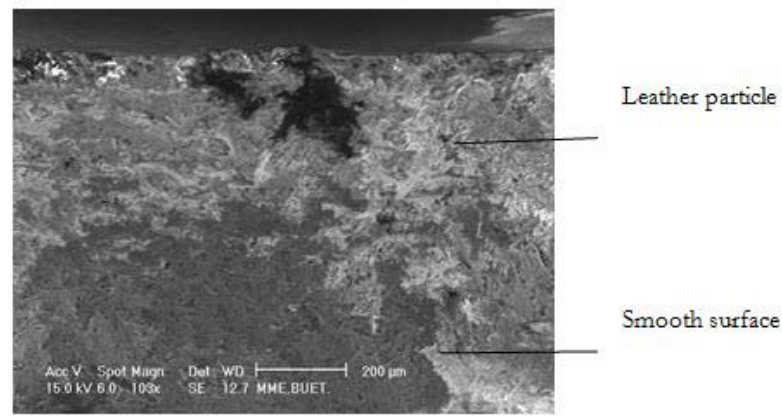

(d)

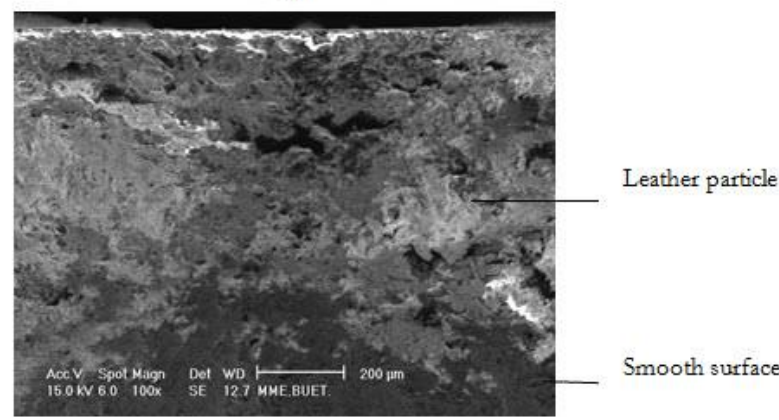

(f)

Fig. 6. Fracture surface morphology of composite (a) only for polyester; (b) 100:5; (c) 70:5; (d) 60:5; (e) 50:5; (f) 40:5 for different ratio of polyester and leather composite.

\section{Conclusion}

Crust scrape Leather-reinforced semi-biocomposite was prepared using solution-impregnation technique. Polyvinyl alcohol (PVA) was added into the matrix solution and the effects of PVA modified polyester matrix on the mechanical and morphological properties of the composites were investigated. Both the mechanical and morphological properties of the composites were improved by the addition of PVA in the composite. The $5 \mathrm{gm}$ leather fiber and 70 gm polyester containing composite showed better improvement in TS, Eb of the composites was also observed for the composites containing $10.85 \mathrm{MPa}$ and $6.82 \%$ respectively. Scanning electron micrographs of the composites showed smooth surface and better matrixfiber adhesion. So it can be concluded that pollution creating crust scrap leather can be reused and recycled into semibiodegradable biocomposite which can reduce environmental pollution and also composite can be used in valuable products.

\section{Acknowledgement}

The authors are grateful to Bangladesh Atomic Energy commission for their Laboratory support and Bangladesh College of Leather Technology for providing lab facilities towards complete this works. 


\section{References}

[1] R. M. Rahman, M. M. Huque, N. M. Islam, and M. Hasan, "Improvement of physico-mechanical properties of jute fiber reinforced polypropylene composites by pos-tratment," Composite: part $A$, vol. 39, pp. 1739-1747, 2008.

[2] T. T. L. Doan, L. S. Gao, and E. Made, "Jute/polypropylene composite I. Effect of matrix modification," Composite Sci and Tech, vol. 66, pp. 952-963, 2006.

[3] M. A. Khan, J. Islam, M. M. Rahman, M. Arifur, R. A. Khan, and T. Islam, "Study on the effect of urea on the mechanical and morphological properties of jute/gelatin composites," P.P. Tech. and Engg., vol. 49, no. 9, pp. 885- 891, 2010.

[4] K. Dey, N. Sharmin, R. A. Khan, S. Nahar, A. J. Parsons, and C. D. Rudd, "Effect of iron phosphate glass on the physico-mechanical properties of jute fabric-reinforced polypropylene-based composites," J. of Thermoplastic mat., vol. 24, no. 5, pp. 695-711, 2001. doi: 10.1177/0892705711401848

[5] J. P. Patel, N. M. Mehta, and P. H. Parsania, "Preparation and physico-chemical study of sandwich glass-jute-bisphenol-c-formaldehyde resin composites," Polymer-Plastics Technology and Engineering, vol. 49, no. 8, pp. 822-826, 2010.

[6] C. I. Hsu, P. H. Ting, and J. R. Hwang, "The effect of process conditions on the fiber orientation and tribological characteristics of polyoxymethylene composites," Polymer-Plastics Technology and Engineering, vol. 49, pp. 1231-1240, 2010.

[7] H. Ozgunay, S. Colak, M. M. Mutlu, and F. A. Polish, "Characterization of leather industry wastes," J. of Environ. Stud, vol. 16, no. 6, pp. 867-873, 2007.

[8] M. Ahmed, "Studies on the effect of titanium salts during tanning and retanning for the production of shoe upper leather," B.Sc. thesis paper, Bangladesh College of Leather Technology, pp. 15-30, 2009.

[9] M. R. Islam, "Preparation and characterization of waste leather reinforced polymeric composite," B.Sc. thesis paper, Bangladesh College of Leather Technology, pp. 15-30, 2009.

[10] J. Prakash, M. Sokolsky, N. Kumar, and A. J. Domb, "Fatty acid based biodegradable polymer," Polymer Reviews, vol. 48, pp. 156-91, 2008.

[11] N. M. Alves, J. L. Mezribells, and J. F. Mano, "Study of the molecular mobility in polymers with the thermally stimulated recovery technique," A Review Journal of Macromolecular Science, Part C: Polymer Reviews, vol. 45, pp. 99-124, 2005.

[12] P. Q. Roderic, L. Youngjoo, and K. Jungahn, "Synthesis of branches polymers: An introduction," Polymer Reviews, vol. 41, no. 4, pp. 369-390, 2001.

[13] R. Ludwig, J. M. Peter, W. Hans-Dietrich, and L. W. Garth, "Interactions between solvents and polymers in the solid state," Polymer Reviens, vol. 15, no. 2, pp. 279-393, 1976.

[14] K. M. Munmaya, "Graft copolymerization of vinyl monomers onto cellulose and cellulosic materials," Polymer Reviews, vol. 22, no. 3, pp. 471-513, 1982.

[15] L. Zhidan and M. Kancheng, "Effect of inorganic filler on the crystallization, mechanical properties and rheological behavior of poly(trimethylene terephthalate)," Polymer-Plastics Technology and Engineering, vol. 46, no. 4, pp. 417-420, 2007.

[16] Z. Guoquan, G. Qiaochun, Z. W. Li, and W. Fagang, "Factors influencing the surface morphology of poly( $\gamma$-benzyl L-glutamate)-block-(random coil polymer) aggregates deposited from the dilute solution," Inter. Jour. of Poly. Mat., vol. 60, no. 4, pp. 290-301, 2011.

[17] C.-I. Hsu, P. H. Ting, and J. R. Hwang, "The effect of process conditions on the fiber orientation and tribological characteristics of polyoxymethylene composites," Polymer-Plastics Technology and Engineering, vol. 49, no. 12, pp. 1231-1240, 2010.

[18] A. Mehdi , J. S. Doetze , L. Katelyn, and B. Mary, "High performance fibers based on rigid and flexible polymers," Polymer Reviens, vol. 48, no. 2, pp. 230-274, 2008.

[19] K. Richard, "Recent advances in polymer fibers," Polymer Reviews, vol. 48, no. 2, pp. 228- 229, 2008.

[20] Z. Yan and W. Li, "Recent research progress on leather fatliquoring agents," Polymer-Plastics Technology and Engineering, vol. 48, no. 3, pp. 285-291, 2009.

[21] H. Ismail, A. M. Norjulia and Z. Ahmad, "Curing characteristics, mechanical and morphological properties of kenaf fibre/halloysite nanotubes hybrid-filled natural rubber compounds," PolymerPlastics Technology and Engineering, vol. 49, No. 9, pp. 938-943, 2010. 